\title{
RETRACTION NOTE: UNDERSTANDING THE LINKAGE BETWEEN SOCIAL CAPITAL AND MAIZE AVAILABILITY EQUIVALENT AMONG SMALLHOLDER MAIZE-LEGUME FARMERS IN KENYA
}

\author{
Robert Ouko GWADA *(D), Zephaniah Ongaga MAYAKA
}

Retraction of: Review of Agricultural and Applied Economics, 23 (1), 83-89. https://doi.org/10.15414/raae.2020.23.01.83-89, published online 31.03.2020

Address:

Egerton University, Faculty of Agriculture, Department of Agricultural Economics and Agribusiness Management, P.O Box 536-20115, Egerton Njoro, Kenya

* Corresponding author: oukogwada@gmail.com

We the authors, are retracting the above regular article as we understand that the paper fell short of the ethical requirements as per the project supervisors.

We understand that the acknowledgement of the funding institution was not properly done.

We are retracting the above article, as we address the issues raised by the Principal Investigator. The concerns are very valid especially around how the citation and acknowledgement were done.

We deeply apologize to the scientific community for this failure.

All authors agree to this retraction.

Retracted: 14.7 .2021 